Jason Baird Jackson (2000) "Ethnography and Ethnographers in MuseumCommunity Partnerships. Practicing Anthropology. 22(4):29-32.

(C) 2000 by the Society for Applied Anthropology. All rights reserved.

Posted to IUScholarWorks Repository in 2008 by the author with the express permission of the Society for Applied Anthropology (email to the author, October 2, 2008).

A note: The author did not have an opportunity to review page proofs or copy edited text for this manuscript, thus the version as published reflects changes made by the journal's editor. While a comprehensive revision is beyond the scope of this posting effort, the article's second sentence would be improved through the deletion of the words "in which." The preferred form would thus be:

Social structures that have supported museums are rapidly changing and cultural diversity is increasingly recognized as both a social value and as a pragmatic challenge for public institutions. 


\section{ETHNOGRAPHY AND ETHNOGRAPHERS IN MUSEUM-COMMUNITY PARTNERSHIPS}

\section{By Jason Baird Jackson}

$\mathrm{D}$ uring the 1999 American Association of Museums (AAM) meetings, museum workers reflected on ways in which their institutions could become more relevant. Social structures that have supported museums are rapidly changing and in which cultural diversity is increasingly recognized as both a social value and as a pragmatic challenge for public institutions.

Although the forms they take are almost as diverse as the American museum community itself, models of direct collaboration between museums and specific local communities (ethnic, religious, occupational, etc.) are becoming a standard part of museumbased exhibition and research. While this common pattern is emerging, there are wide gaps existing between the aspirations and rhetoric of museum advocates of collaboration and the real work done throughout the United States. What is often missing in collaborative exhibition projects exploring local artistic, cultural, or historical traditions are the values and perspectives that are the common background of professional cultural anthropology and folklore research. In this essay I present, as a case study, an account of a collaborative exhibition project at Tulsa's Gilcrease Museum where I, until recently, served as Curator of Anthropology.

As in such fields as nursing, cultural studies, art history, and education, there is an increasing tendency among museum professionals to appropriate the methods developed in ethnographic fields and to turn them toward very instrumental, short-term ends without the benefit of the longer-term perspective that most anthropologists and folklorists learn to accept during their professional socialization. If the recent AAM meetings provide any evidence, the proverbial wheel seems to be being

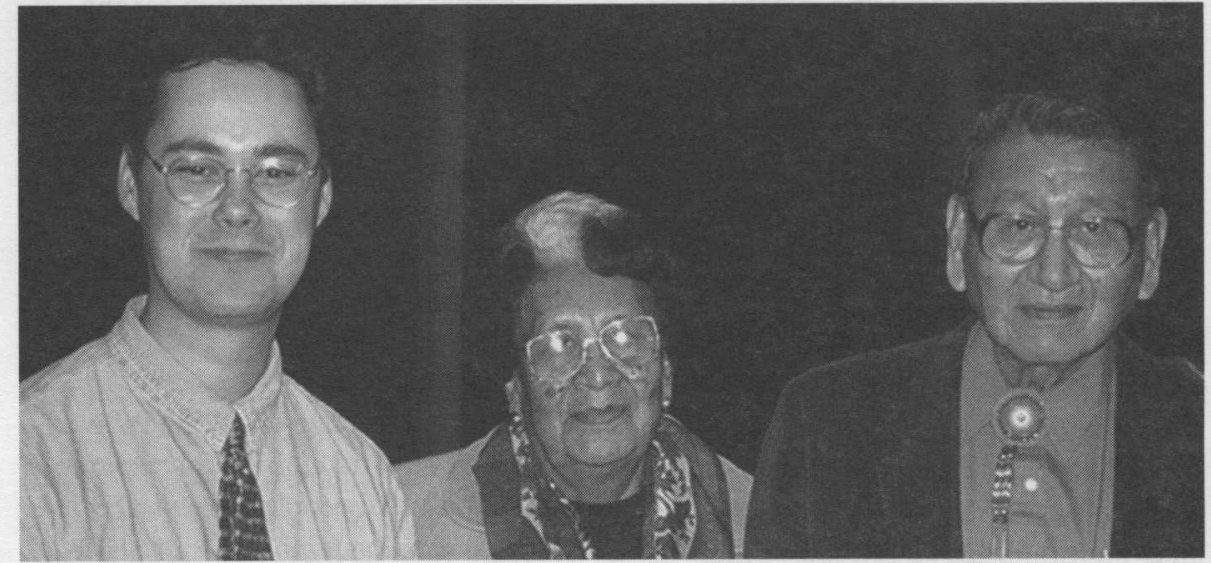

Jason Baird Jackson (left) with Thelma Cahwee and Mose Cahwee at the Euchee Heritage Days Reception, Gilcrease Museum, 1997

reinvented a great deal at present. Rather than stand by while the museum world invents its own "pidgin" anthropology, anthropologists and folklorists should recognize the possibilities emerging for taking on new roles in museum settings. Museum collaboration is an area where both practicing and academic anthropologists can make valuable, short-term contributions to the diverse publics that museums serve and to the specific communities to which they maintain long-term ties. Although I have ongoing professional relationships with museums, my hope is that my own case will provide an example for ethnographers working outside museums. Increasing the number of collaborations linking local communities, ethnographic practitioners, and museums would strengthen the position of applied anthropology and public folklore, improve the ways museums do their work and, when done well, serve the interests of the peoples with whom we work.

My own background is as an ethnographer employed, between 1996 and 2000, as an anthropologist in a hybrid art-history-anthropology museum. This configuration of disciplines is unusual in the social organization of American museums, but it seems to me to hold particular promise for advancing museum work relevant to local communities. It also offers great opportunities to further critical and constructive approaches to cultural studies generally. On the art side, a survey of the current avant garde in both art and art history, reveal a strong impulse to emulate the concerns and modus operandi of anthropology, even when the source of these methods and theories remain unexamined. In academic history, the intercourse between the two fields has been more clearly institutionalized in meetings, journals, and theoretical projects, such as the "new cultural history" practiced by historians and in the field of ethnohistory pioneered by American anthropologists. The emergence of museums of cultural history, such as the Fowler Museum at UCLA suggest the effect that such trends have had among museums.

At Gilcrease Museum, this exciting combination was born of the collecting interests of our founding patron but, as a public institution, the full range of possibilities this mixture of disciplines represents has never been as fully realized. In practice, Gilcrease Museum has cycled between being a conventional regional art museum (in both 
senses of "regional") and being a rather unreflective museum of western North American history, emphasizing the more picturesque and less horrifying aspects of European-American manifest destiny. For reasons both contingent (such as staff changes) and general (such as the emergence of federal repatriation law), the middle and late 1990 s saw a swing in the direction of anthropology at Gilcrease Museum.

\section{The Project}

\section{Emblematic of this shift is an} exhibition organized during 1996 and 1998 and featured at Gilcrease during the fall of 1998. After sketching the background and lessons of this project, an exhibition titled "Children of the Sun: Euchee Indian Culture and Tradition," I return more generally to the prospects of using ethnography as a method for building community relevance in museums and to the prospects for anthropologists taking a greater role in the practice of exhibition building.

Since the late 1980s, the Yuchi (a.k.a. Euchee) people of Eastern Oklahoma have been deeply involved in an effort to increase public awareness of their unique plight as an unrecognized Native American people and to protect and enhance knowledge within the tribe of its distinctive language, culture, and history. Yuchi willingness to work directly with outside scholars derives from this general interest and from the pragmatic requirements of the Bureau of Indian Affairs' criteria for unrecognized Native American nations seeking federal acknowledgement. The acknowledgement process requires documentation of a community's status as a distinct people in the present and through time. This purpose, in particular, has led to Yuchi efforts to attract and direct the attention of anthropologists. This is the applied context within which I have undertaken collaborative ethnographic fieldwork with the Yuchi people since 1993, working particularly with the chiefs of the three Yuchi settlements and with other Yuchi cultural leaders.

Lacking federal recognition and politically incorporated within another tribe-the Muskogee (Creek) Nation, there is very little awareness of the Yuchi among the people of Oklahoma. This factor was one motivation leading to Yuchi interest in organizing an exhibition presenting their culture and history.

Another Yuchi motivation for the exhibition was an exciting undertaking that they began about 1991. This first major project of the ongoing Yuchi cultural revival was the building of a community photographic archiveborrowing family photos and making community copies of them. With only a handful of Yuchi images in public repositories, this project generated a wealth of information about the tribe, as well as an important historical resource by and for Yuchi people. This project led to the publication by the tribe of photographic calendars, annually since 1992, and an important photographic history edited by tribal members (E.U.C.H.E.E., 1997, Euchees Past and Present. Sapulpa, Okla.: Euchees United Cultural, Historical, and Education Effort, ). By 1996, this work on photographs had generated interest in organizing a public viewing of selected images. At this point my own doctoral research was nearing completion and our interests in an exhibition began to coalesce and merge.

Concurrent with my Yuchi community involvement, I began work with Gilcrease Museum, initially part-time as a Research Associate and then as Assistant Curator of Anthropology. My full-time appointment as Curator of Anthropology came just before the Children of the Sun exhibition opened in August 1998, so for most of the project's history, I existed at a halfway point between the museum and the Yuchi community. In this instance, this was a particularly good position to occupy.

In my graduate training, my teachers had exposed me to the idea that a museum exhibition is a good transitional product bridging field research and ethnographic writing for broader audiences. If organized in or near the local community with whom one works, it is a relatively accessible opportunity for one's collaborators to see the fruits of their efforts. The difference between a multi-media exhibition and a 400 page academic dissertation, in terms of general community appeal, are plain enough to recognize, I think.

Children of the Sun represented a convergence of these interests. First, it met the Yuchi's political need to increase awareness in the general public and among policymakers of their situation, today and in the past. Secondly, it fulfilled a desire of community cultural leaders to further awareness of tribal traditions among Yuchi people. Thirdly, my own interest in assisting the Yuchi in these areas was advanced. Also, the exhibition was an opportunity in which I could share the things Yuchi elders had taught me with the Yuchi people as a whole and with the region's general public. To these purposes was joined, a less enthusiastic interest within the museum to enter new relationships with minority communities. I say less enthusiastic, because in contrast to these other agendas, the museum's interests are diffuse and multifaceted. In investing in me, and through me, in the Yuchi people, the museum was being as much opportunistic as strategic. Similar conditions likely govern comparable projects and museums elsewhere.

Planning for the exhibition was supported by a grant jointly awarded to the museum and the tribe by The Fund for Folk Culture, under a program funded by the Lila Wallace-Reader's Digest Fund Community Folklife Program. The trick here was to convince a funder to support an open-ended exhibition planning effort that had, as one of its possible outcomes, a decision by the Yuchi community not to proceed with the exhibition. We overcame this by building a community arts festival into the planning project. Each Yuchi community gathering or meeting of the exhibition planners was divided into discussions of the exhibition and planning for the festival. The first Euchee Heritage Days became a standalone event, realizing a pre-existing goal of the tribal leaders. For the exhibition process, the Heritage Days served as a conclusion for the planning process. Having succeeded in attracting community and museum support for the project, the festival was the venue in 
which the exhibition plan was shared with both constituencies.

Thankfully, The Fund for Folk Culture, staffed and advised by professional folklorists, is particularly sensitive to the kinds of issues our exhibition project was intended to address. They were probably more open to the notion that an entire community, person by person, would need to be canvassed for approval and support than was the Gilcrease staff. Certainly, the linkage of folk festival and exhibition was a familiar model to public folklorists trained in ethnographic methods.

The planning phase took place over a ten-month period. A key participant was Elenora Powell, a Yuchi tribal member who served with me as co-curator on behalf of the tribe. Also central to the project were planning committee members from the community. This group was mostly composed of elders who are leaders in ongoing community activities. In addition, public focus group meetings were held in each of the Yuchi settlements. These gatherings spread information about the project widely, garnered support from less active community members, and fed ideas to the project planners. By the time the exhibition opened, widespread knowledge of it, and support for it, existed among the Yuchi people. We estimate $80 \%$ of the Yuchi community living in Oklahoma visited the exhibit.

\section{Outcomes}

Several outcomes of the process are worth noting. For Yuchis, a fundamental benefit was access to old collections obtained on loan for the exhibit. This is perhaps the easiest benefit museums can bring to the table in their collaborations with minority communities. For the museum, collecting new works by contemporary artists and craftworkers was a gain, the full impact of which was not anticipated until the project was completed.

In terms of design, the exhibit, while an advance for our museum, was rather traditional in style. Given the opportunity to shape the physical form of their exhibition, it should not be surprising that Yuchi people consciously or uncon- sciously presented their story in familiar packaging. In creating a conventional exhibition, Yuchi people presented their own ways of life never interpreted in an exhibition before. This put them on par with peoples and traditions more frequently interpreted in museum settings.

While presentations by commercial Native American artists have been a long-term staple of Gilcrease Museum's programming, the project's commitment to putting community elders in the lead was particularly successful in public programming. The extended planning process helped these presenters develop new found comfort in sharing their knowledge in what would otherwise have been a very foreign setting. Visitors uncomfortable with academic lectures and the formal conventions associated with museum programs were attracted to, and engaged by, elders first hand sharing of their own personal experiences. Advertising for programs emphasized this down-to-earth, personal approach, and events were framed as interactive and participatory. A Yuchi "traditional foods tasting" was a typical program.

Beyond the successes realized by Yuchi community leaders, the Children of the Sun exhibition was a provisional success in the terms of the pragmatic measures of museum success. It provided expanded visitorship, possessed visual interest, offered informational content, and generated positive publicity. Among the Yuchi and other Native peoples of Northeastern Oklahoma there is a better appreciation of Gilcrease Museum. Native American visitation and tours are up and we were voted the state's best museum in a Native American community poll. These things, in particular, are positive gains.

\section{Discussion}

Politically, the project faced real challenges. More expensive than previous Gilcrease exhibitions focused on Native American traditions and organized in an institutionally unfamiliar way, implementing the project required extra effort to fund. As a new approach to exhibits, the project was never fully understood by the staff as a whole and never had its complete support. Speaking subjectively, I feel the museum as a whole grew through the exhibit project, but I would be naïve to think that everyone involved has internalized its lessons. The museum now has direct experience with a more democratic and plural approach to exhibitions. The museum now has a model, built on ethnographic methods, for engaging with communities otherwise disconnected from the museum. Whether the museum will continue to explore the possibilities, such a project represents remains to be seen. Without outside pressure, commitments to diversity are difficult to generate and sustain internally and are difficult to translate into projects in the real world.

To talk about using ethnography as a tool for creating community relevance is a very different thing from describing or advocating museum ethnography or museum anthropology. Ethnographers have long found institutional homes in museums, but the primary objective of museum anthropology, from its golden age to the present, has been the production of knowledge about cultures, not reshaping the institutions in which it dwells. I think most museum professionals are reflexive enough to recognize that talking about community relevance is itself a significant process grounded in changes in society at large. It is a shift in perspective that recognizes the museum both as a powerful force for challenging or reaffirming existing social orders and as only one node among institutions of cultural reproduction.

I think that ethnography can assist museums in negotiating the current state of cultural change, both in the museum world and in society more broadly. Most importantly, I think that ethnographers working in the service of museums can overcome some of the many obstacles that prevent all communities from participating and investing in the life of their local museums. That said, I am profoundly worried about advocating wholesale, do-it-yourself, ethnography, a prospect floating just below the surface in countless discussions ongoing throughout the community of museum professionals. 
The best presentation I heard at the 1994 American Anthropological Associating meetings was delivered not by an anthropologist, but by art historian Hal Foster. Examining the relationship between art and anthropology, he documented a current trend in public art projects. He began by observing that artists currently find the image of the ethnographer compelling, and in some cases clearly romantic. For an artist to take on the persona of ethnographer is to expand the marginal identity artists in our society already strive to claim. Ethnographers transgress social boundaries and engage in cultural criticism from a position between cultures and outside society-appealing activities for contemporary artists. In contemporary public art, civic leaders, concerned with the appearance of community relevance engage artists who identify themselves with nondominant groups, but, as artists of broader reputation, do not themselves come from the local community. The standard strategy described by Foster is for the local elite to bring the would-be artist/ethnographer into town for focus group meetings or other encounters with preselected representatives of the community's "others." In a subsequent essay, Foster has described the ways institutions and their leaderships use such processes of pseudo-ethnography to inoculate themselves from real criticism on questions of relevance, engagement, and pluralism (The Artist as Ethnographer? In The Traffic in Culture: Refiguring Art and Anthropology. Edited by George E. Marcus and Fred R. Myers. Pp. 302-309. Berkeley: University of California Press, 1995). A city near Tulsa, Oklahoma recently dedicated a monumental sculpture of a 19 th century Ponca Indian leader. In a juried competition for the commission, a Navajo sculptor was selected for the project. Developing the work, the artist visited and made acquaintance in the local community but, as Foster describes for the general pattern, this contact was brokered by the local cultural-political elite. From an Anglo perspective the community came together to honor local American Indian culture and history. From a traditional Ponca point of view, nothing has been gained. A Navajo artist with Santa Fe art world credentials has represented Ponca experience on the basis of fleeting encounters and a construction of common Indian-ness that is a product of the Anglo imagination. Exhibit organizers in museums face the same dangers of using psuedo-ethnography to build false relevance. The real work of fostering inclusion is much more difficult than organizing a few focus groups and a naïve willingness to open the doors to non-Anglo visitors.

\section{Conclusions}

The success of the Children of the Sun exhibit and others like it, was predicated not only on extended, collaborative exhibition planning process but with engagements by fieldworkers over longer periods. For museums with anthropologists and folklorists on staff, this kind of engagement is a benefit of long-term research projects joined with personal commitments to the people of local communities. For museums seeking such longterm engagement, but lacking professional ethnographers on staff, a better route, I would suggest, than a crash course in "guerilla" fieldwork methods, is to engage with individuals who are already making such lifelong commitments. Working in almost every local community there are ethnographersstudents, professors, and community scholars, both group members and outsiders who have formed deep attachments to it, who are prepared to help bridge the local cultures of community and museum. Professional anthropologists and folklorists today are debating community relevance just as actively as museum professionals are. While many professionals in these fields are unwilling to devote a life to exhibition work, most would jump at the opportunity to bring their own ethnographic work to wider audiences, while helping to give the people with whom they collaborate a voice in the larger public sphere of the museum. Museums interested in engaging with socially and culturally diverse groups would do well to seek out those who are already familiar with them and who have the training to translate in both directions across the frontiers separating museums and local communities. Such opportunities represent new avenues for practicing anthropologists and public folklorists, but they also represent a unique chance for scholar-researchers based in the academy to bring their work and their commitments to larger audiences.

\section{Jason Baird Jackson has recently} become Assistant Professor of Anthropology and Assistant Curator of Ethnology at the Sam Noble Oklahoma Museum of Natural History at the University of Oklahoma. Through the summer of 2000 , he served as Curator of Anthropology at Gilcrease Museum in Tulsa, Oklahoma and as Research Associate Professor of Anthropology at the University of Tulsa. He earned a Ph.D. in Cultural Anthropology and an M.A. in Folklore from Indiana University. In addition to Yuchi ethnography and museum anthropology, Jackson's research focuses on the social organization of cultural performance among the Woodland peoples of Eastern Oklahoma. A book on Yuchi community life, based on his dissertation is to be published soon by the University of Nebraska Press. He published an assessment of museum anthropology vis$\grave{a}$-vis applied and academic anthropology in the Anthropology Newsletter 40(5). In addition to museum work, Native American language retention and the federal acknowledgement process have been applied foci for his research. Seeking to continue the Gilcrease Museum's efforts at building ties to local communities, he initiated a survey of African American arts and culture in Oklahoma during 1999. The exhibition profiled in this essay was funded by The Fund for Folk Culture/Lila WallaceReader's Digest Community Folklife Program, the Oklahoma Arts Council, and CITGO Petroleum Corporation. Jason Baird Jackson can be reached at Sam Noble Oklahoma Museum of Natural History, University of Oklahoma, Norman, OK 73019, USA. His Email is <jjackson@ou.edu>. 